\title{
Discussing conflicts of interest during a Kettil Bruun Society symposium, June 2014, Turin (Italy)
}

\section{Editorial}

Human beings have always sought after truth and made efforts to define and measure objects and events outside and inside themselves. In the last four centuries, since the time of Galileo, scholars came to agree more and more on a scientific method that could be shared in order to obtain replicable results that could become a common good for humanity. The results of a study can in fact lead to technological applications in various sectors of human life, like education, commerce, industry, and health.

The search for scientific truth and its relationship with the economy has always had a complicated life: first, because in any given moment there will be different ideas about truth, and second, because researchers need both the means and the time to conduct their work. This is why a researcher must either support him- or herself and/or be financially supported by someone that may have different expectations about the research results.

Thus, this involves the integrity of both the individual researcher and his/her referral network-the "scientific community"- that can call into question their ethical sphere by a potentially problematic relationship with truth, economy, and utility.

The issue of conflicts of interest (COI), and the related concerns, have been often discussed in the recent years among researchers and public health experts, as well as within the area of alcohol studies (e.g., Babor \& Miller, 2014). For this very reason a roundtable on COI was organized at the Kettil Bruun Society for Social and Epidemiological Research on Alcohol (KBS) Annual Symposium in Turin, Italy, in 2014. Several important themes were raised by the highly experienced scholars who attended the roundtable, and who made the courtesy for us to report their oral presentation in a short paper. The papers are presented in the following pages.

In this introduction we summarize and comment on the contributions of these authors. The discussion in Turin, like others that have occurred during the last years, focused mainly on the conflicting relationship between researchers and funds provided by the alcohol industry, due to the industry's interest in showing alcohol consumption in the best possible light regarding the wellbeing of the individual consumers. According to Babor (2016), "Industry funding increases the likelihood that researchers will produce proindustry results." This leads researchers to question whether to seek or accept funding from the alcohol industry that could threaten their autonomy and reputation, even if in some countries such funding may have no substantial alternative (Room, 2016).

Particularly in the field of alcoholic beverages, drugs, and other addictions, "which is not of central interest to any traditional academic discipline or profession, the funding is usually given within a frame of institutional interests of the funder” (Room, 2016). Beyond firms involved in producing, distributing, or marketing alcoholic beverages, the funder is often a "government department or research fund. Less commonly, it may be a charitable organisation. Or it may be a commercial organisation" with interests in the area, such as insurance companies and pharmaceutical firms that fund research on medications for alcohol-related conditions (Room, 2016).

More generally, a conflict of interest can be defined as "a situation or relationship in which professional, personal, or financial considerations could be seen by a fair-minded person as potentially in conflict with independence of judgement" (Farmington Consensus, quoted in Babor, 2016). Of course, one important problem of COI is that it can lead to a decrease in the flow of reliable information.

One underlying assumption of this argument is that if the researcher has no external conflicts with any agency, he or she would have an independent judgment. Unfortunately, it is difficult to find a researcher, editor, or reviewer who is totally unaffected by other considerations than the search for truth (Stenius, 2016). Nowadays it is almost universally accepted, in line with the ideas of Kuhn (1970), that the choice of a research problem, the material collected for a study, and the focus of the analysis are deeply influenced by the interests of individual scientists, funding parties, and society as a whole - or, as Room (2016) put it, by the researcher's "intellectual and cultural-political heritage and environment". In fact if "the power of knowledge derives from disinterest," disinterest is never absolute, and scientists work in networks of often invisible prestige, reputation, and other forms of symbolic power that have value and arouse interests (Sulkunen, 2016). 
The special attention to COI in the scientific community today may arise from a sort of skepticism about the real capacity of the scientific method to produce replicable results to refute or, conversely, to corroborate the research hypothesis; or it could reflect the belief that researchers remain neutral in their study of reality.

The interaction between subject and object, which is able to alter both parties, has been argued both in psychotherapy (e.g., the "personal equation" described by Jung [1989]) and in physics (e.g., the interference between the observer and the observed described by Heisenberg and Schrödinger since the 1920s [Stanford Encyclopedia of Philosophy, 2006]). The remedy provided for psychotherapists is that they themselves should undergo psychotherapy in order to be aware of their personal views and not to attribute them to people in treatment. But in general, the criteria of the scientific method have been set as bastions, precisely in order to limit the subjectivity of the scholar.

Overall, as reported above, the contributions of authors in the following pages pointed the light primarily towards the COI of a researcher or group of researchers (or a scientific community) in search for scientific truth, due to funding by the alcohol (particularly spirits and beer) industries. Other sources of similar COI were also mentioned: professional prestige, career advancement, the specific agendas of public funding, the aims of university research, as well as the researcher's personal and cultural assumptions. All these can create problems of credibility, both for the scientific community and for the individual scholars, that may remain hidden-deliberately or unwittingly-to scientists themselves. One result may be that researchers think twice before publishing results that go against the power of their funders, institute, or university. As a colleague from the audience of the roundtable claimed, "I don't want to bite the hand that feeds me." A reverse consideration would be that the alcohol industry would be really "interested in the 'independence' of the researcher" not in the ethical sense but in political-economic terms. "They want to buy an unbiased opinion, conclusions, ideas . . . because the researcher can be trusted" (Lemmens, 2016).

At the opposite side of the conflict between the alcohol industry and research, one may take into account their cooperation as a type public-private partnership. Unfortunately, the road is marked by many unsuccessful examples, as the industry appeared "unwilling to accept any restrictions in their dealing with the research field" (Lemmens, 2016), or, according to other authors, alcohol signatory pledges appear to have committed to actions that the industry would have undertaken anyway (Knai et al., 2015).

We could add that words do matter and that a different definition of terms could perhaps help make the relationship between the two sides less difficult. In a recent JAMA editorial, Cappola and FitzGerald (2015) claimed that speaking of COI is likely to cast a negative shadow on even commendable forms of cooperation between the interests of research institutes and those of private sponsors. The authors suggest changing the terminology to "confluence of interests," since "conflicts of interest" is overly "confrontational and presumptive of inappropriate behaviour," as well as pejorative. Confluence of interests, on the other hand, implies an alignment of primary interests (to benefit patients and society) and secondary interests (financial and professional nature); and it "represents a complex ecosystem that develops a uniform approach to minimize bias in clinical research." According to the authors, "such policy must be at once simple and accessible, capturing the complexity of the relationships while being sufficiently flexible at the individual level as not to intrude on the process of innovation."

Anyway, conflicts have to be governed. During the KBS discussion in Turin, as is shown in the following papers, authors paid attention to adequate management of COI between research and the alcohol industry. Recommendations ranged from outright bans on the acceptance of industry funding (Babor, 2016), creating a firewall among the industry-funded studies and the remaining ones, to the intensification of peer review procedures, to the increase in transparency, and to the sensible requirement to declare COI as an integral part of all serious addiction journals (Stenius, 2016).

In the end, we must remember that, as Room remarked, "research should be judged by its inherent quality and contribution to knowledge" (Room, 2016). Thus, a crucial test to assess both the scientificity of a study and the ethics of the researcher would be to compare industry-funded and non-industry-funded alcohol research. Room cited one preliminary study, carried out by two authors who are above suspicion of being complicit with the alcohol industry, that aimed to make such a comparison and did not find statistical evidence of the effects of alcohol industry funding on the results of a study for cardiovascular disease mortality (McCambridge \& Hartwell, 2015). Similar studies are certainly needed to bring more clarity in this troubled area.

\section{Acknowledgments}

Thanks to Deborah R. Gordon for her comments to the text, and to Eugenio Racalbuto for transcribing the interventions material.

\section{References}

Babor, T. E., \& Milller, P. G. (2014). McCarthyism, conflict of interest and Addiction's new transparency declaration procedures. Addiction, 109(3), 341-344.

Babor, T. E. (2016). How should we define, document and prevent conflict of interest in alcohol research? The International Journal of Alcohol and Drug Research, 5(1), 5-7.

Cappola, A. R., \& FitzGerald, G. A. (2015). Confluence, not conflict of interest: Name change necessary. JAMA, 314(17), 1792-1792. doi:10.1001/jama.2015. 12020 
Jung, C. G. (1989). The psychology of transference. London, England: Routledge and Kegan Paul.

Knai, C., Petticrew, M., Durand, M. A., Scott, C., James, L., Mehrotra, A., . . . Mays, N. (2015). The public health responsibility deal: Has a public-private partnership brought about action on alcohol reduction? Addiction, 110(8), 1217-1225.

Kuhn, T. S. (1970). The structure of scientific revolutions (2nd ed.). Chicago, IL, United States: University of Chicago Press.

Lemmens, P. (2016). Critical independence and personal integrity revisited. The International Journal of Alcohol and Drug Research, 5(1), 13-14.

McCambridge, J., \& Hartwell, G. (2015). Has industry funding biased studies of the protective effects of alcohol on cardiovascular disease? A preliminary investigation of prospective cohort studies. Drug and Alcohol Review, 34(1), 58-66.

Room, R. (2016). Sources of funding as an influence on alcohol studies. The International Journal of Alcohol and Drug Research, 5(1), 15-16.

Stanford Encyclopedia of Philosophy. (2006). The uncertainty principle. Retrieved from http://plato. stanford.edu/entries/qt-uncertainty/

Stenius, K. (2016). Addiction journals and the management of conflicts of interest. The International Journal of Alcohol and Drug Research, 5(1), 9-10.

Sulkunen, P. (2016). Knowledge is power, and power is knowledge. The International Journal of Alcohol and Drug Research, 5(1), 11-12.

Allaman Allamani, M.D.

Agenzia Regionale di Sanità Toscana

Villa la Quiete alle Montalve, via Pietro Dazzi 1

50141 Firenze - Italy

E-mail: allamana@gmail.com

Franca Beccaria, Ph.D.

Eclectica, Institute for Research and Training

Turin, Italy 